\title{
On the Fire Performance of Double-shear Timber Connections
}

\author{
LEI PENG ${ }^{1,2}$, GEORGE HADJISOPHOCLEOUS ${ }^{3}$, JIM MEHAFFEY $^{2}$, and MOHAMMAD \\ MOHAMMAD ${ }^{2}$ \\ ${ }^{1}$ Canada Wood Beijing \\ Room 1507, Kuntai International Mansion, No.12B \\ Chaowai Street, Beijing, 100020, China \\ ${ }^{2}$ FPInnovations \\ Suite 4100 - CTTC, 1125 Colonel By Drive \\ Ottawa, ON, K1S 5R1, Canada \\ ${ }^{3}$ Department of Civil and Environmental Engineering \\ Carleton University \\ 1125 Colonel By Drive \\ Ottawa, ON, K1S 5B6, Canada
}

\begin{abstract}
In heavy timber structures, double-shear connections, including wood-wood-wood (WWW), wood-steelwood (WSW) and steel-wood-steel (SWS) connections with either bolts or dowels as fasteners, are widely used to assembly structural members and transfer loads. However, connections with metal fasteners and components are potentially venerable links in fire exposure. A number of efforts have been devoted to study the fire performance of timber connections in the last two decades. With the knowledge and experimental data generated, new attempts have been made in order to develop new calculation methods and improve design rules for timber connections in fire. In this paper, existing models are discussed and new correlations are presented for the calculation of the fire resistances of double-shear timber connections. Various factors, i.e. timber thickness, fastener diameter, and load ratio are considered in the correlations. Comparison between the predictions using the correlations and the measured results in fire resistance tests shows good agreement. For timber connections with protective membranes, the component additive method (CAM) can be used by adding the additive fire resistances of the protective membranes to the fire resistances of unprotected timber connections. Connections with concealed fasteners and intumescent paint are also discussed in this paper.
\end{abstract}

KEYWORDS: timber, connections, fire resistance, structural design.

\section{NOMENCLATURE LISTING}

$\begin{array}{ll}a_{f i} & \text { additional thickness according to Eurocode } 5(\mathrm{~mm}) \\ d & \text { fastener diameter }(\mathrm{mm}) \\ d^{*} & \text { non-dimensional fastener diameter } \\ k & \text { connection factor in Eurocode } 5 \\ M & \text { correlation factor } \\ N & \text { correlation factor } \\ R_{O} & \text { ultimate load at ambient temperature }(\mathrm{kN}) \\ F_{f i} & \text { applied load in fire }(\mathrm{kN})\end{array}$

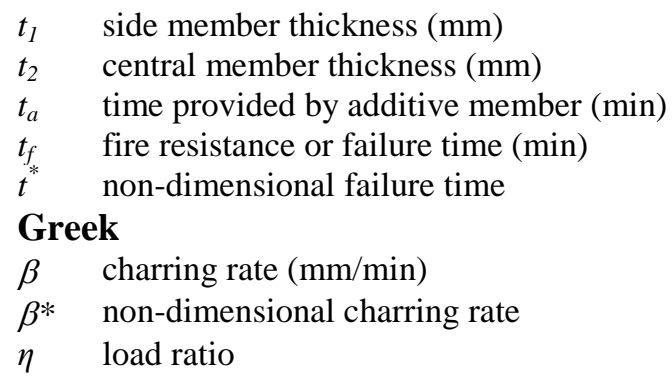

\section{INTRODUCTION}

Timber structures tend to fall into two distinct categories: light framing timber constructions and heavy timber structures. Heavy timber structures are those which use large size sawn timber, glue-laminated timber or other wood composite products as principal structural elements such as beams, columns, decks or truss members. In heavy timber structures, bolts, dowels and steel plates are popular connectors since they are able to carry heavy loads. Figure 1 shows different types of double-shear timber connections.

Heavy timbers are recognized as having good fire resistance even if they are exposed to fire directly. This is because the charred layer on the exposed surface acts as a thermal barrier for the solid wood below, preventing the attack of flame and blocking oxygen penetration. However, timber connections are 
recognized as the weakest link in a timber construction in fire and they normally govern the fire performance of the timber construction. This is because metal fasteners and components, which are normally used in timber connections, heat up quickly and lose their stiffness and strength at high temperatures. They also transfer heat into the interior of wood members and cause wood to char faster because of the high conductivity of metal. Therefore, the capacity of timber connections with metal fasteners can be reduced to a great extent. The analysis of the fire performance of timber connections is very complicated because there are various connection types, different geometries and fastener arrangements, and also because of the great variability of the properties of wood and char at elevated temperatures.

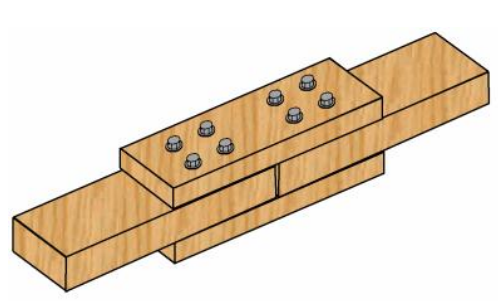

(a)

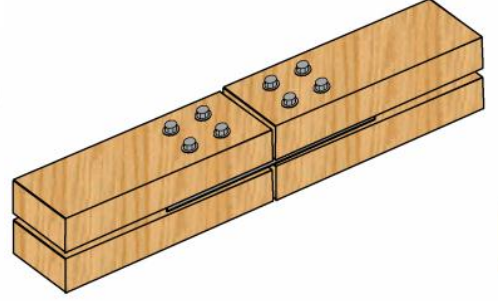

(b)

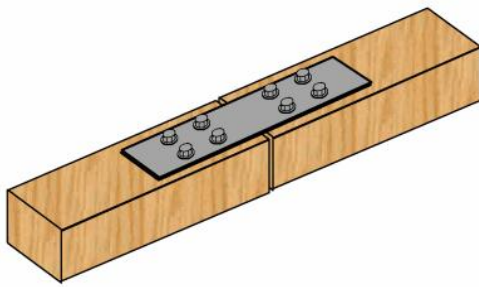

(c)

Fig. 1. Double-shear timber connections: (a) wood-wood-wood connection; (b) wood-steel-wood connection; (c) steel-wood-steel connection

Prior to the 1990s, knowledge of the fire performance of timber connections was limited [1]. In the last two decades, this area has received a great deal of attention. A number of experimental research efforts have been devoted to study the fire resistance of timber connections under standard fire exposures. The fire resistance test results from France [2-5], New Zealand [6-8] and recently from Canada [9] have provided a certain amount of knowledge and experimental background on the fire performance of WWW, WSW and SWS connections using either bolts or dowels as fasteners. The exposure conditions were either ISO 834 [10] or ASTM E119 [11].

In Canada, the structure of most buildings permitted to be of combustible construction must have either a $45 \mathrm{~min}$ or $1 \mathrm{~h}$ fire resistance rating [12]. However, neither the National Building Code of Canada (NBCC) [12] nor any other Canadian document provides detailed information on the estimation of the fire resistance for different connection types and geometries [13]. In US, TR 10 assumes that the protection of wood panels, fire-rated gypsum boards or coatings can provide the entire $1 \mathrm{~h}$ fire resistance rating, but does not take into account the inherent fire resistance of the connection itself [14]. In Europe, a simple empirical approach, called as the reduced load method, is available but very limited since it is based on a limited number of fire tests and only one parameter is included in the method [15].

Analytical and numerical models were carried out to evaluate the fire resistance of timber connections [8,9,16-18]. However, these models require accurate time-dependent temperature profiles in the connections and a sophisticated heat transfer analysis is required. In addition, to calculate the strength of the connections in fire, integration of the non-linear strength along the fasteners (due to temperature gradient) is also required. The calculation process is complicated and time consuming.

For design purposes, it is of great importance to develop new simple, yet accurate methods to calculate the fire resistance of timber connections. The variabilities of connection type, fastener type, load ratio, and wood member and fastener dimension must be considered in the methods.

This paper firstly presents an overview of the available models. Then, new correlations are introduced and used to predict the fire resistances of unprotected WWW, WSW and SWS connections. The comparison between the predictions using the correlations and the test data shows good agreement. The additive method is also adopted to calculate the fire resistance ratings for protected timber connections. 


\section{EXISTING MODELS}

There are a number of existing models that have been developed to determine the fire resistance of timber connections. This includes empirical rules in Eurocode 5 [15], analytical models, embedment reduction methods [8,9,17], component models [16], and thermo-mechanical numerical models [18].

\section{Eurocode 5 Method}

In Eurocode 5 - Part 2 [15], simplified rules are adopted for unprotected connections. The code states that connections satisfying Eurocode 5 - Part 1 for normal temperature will have a fire resistance of either $15 \mathrm{~min}$ (nails, screws, bolts) or $20 \mathrm{~min}$ (dowels).

Alternatively, a calculation model called the reduced load method is adopted in Eurocode 5. This simplified model is a one-parameter exponential relationship between the fire resistance time and the load carrying capacity, given as:

$t_{f}=-(1 / k) \ln \left(F_{f i} / R_{0}\right)$

$k$ is the connection parameter for different type of connections given in Eurocode 5. The reduced load model is based on a limited number of fire resistance test results for nailed timber connections (Noren [19]) and bolted or doweled timber connections (Dhima [3]). As reported by Konig [20], the reduced load model could be correct for some cases but conservative when thick side members of timber are used.

For greater fire resistance, member sizes should be increased with an additional thickness, but the proposed equation for calculating the additional thickness in Eurocode 5 is limited to a fire resistance rating not more than $30 \mathrm{~min}$.

\section{Embedment Reduction Model}

The embedment reduction model was initially proposed by Noren [19] to predict the fire resistance of nailed timber connections. The model is based on Johansen's yield model [21] by replacing constant embedding strengths at normal temperature with reduced values at high temperatures. Later on, this model was adopted by researchers $[8,9,17]$ to investigate the fire resistance of timber-to-timber connections and timber-to-steel connections with bolts and dowels.

Moss used the embedment reduction model [8] to calculate the fire resistance of bolted timber connections. Moss' research was based on Lau and Chuo's experimental research work [6,7]. The connection strength obtained in heating tests at elevated temperatures was substituted back to Johansen's yield equations to determine the embedding strength as a function of temperature, and then this temperature-based embedding strength was used to calculate the strength of the connection in fire exposure.

However, different approaches were used by Noren and Moss in the embedment reduction method. In Noren's approach, the temperatures at $0.5 d$ away from the fastener/wood interface (where $d$ is the fastener diameter) were used to calculate the embedding strength, and the embedding strength decreased rapidly as the temperature increased. Noren also commented that the moisture effect in the wood was considered in the relationship of the embedding strength vs. the temperature, since the moisture movement and accumulation driven by the heat have impact on the strength. While in Moss' approach, the temperatures at the fastener/wood interface were used to determine the embedding strength, and the embedding strength at elevated temperatures was determined based on pre-heating tests without considering the moisture effect. To overcome the result that a connection could not carry any load when the interface temperature reaches over $300{ }^{\circ} \mathrm{C}$, Moss assumed that wood had a residual embedding strength, approximately $20 \%$ of the ambient embedding strength above $270^{\circ} \mathrm{C}$. Fig. 2 shows the relationships between the embedding strength and the temperature, used by Noren and Moss, respectively. 


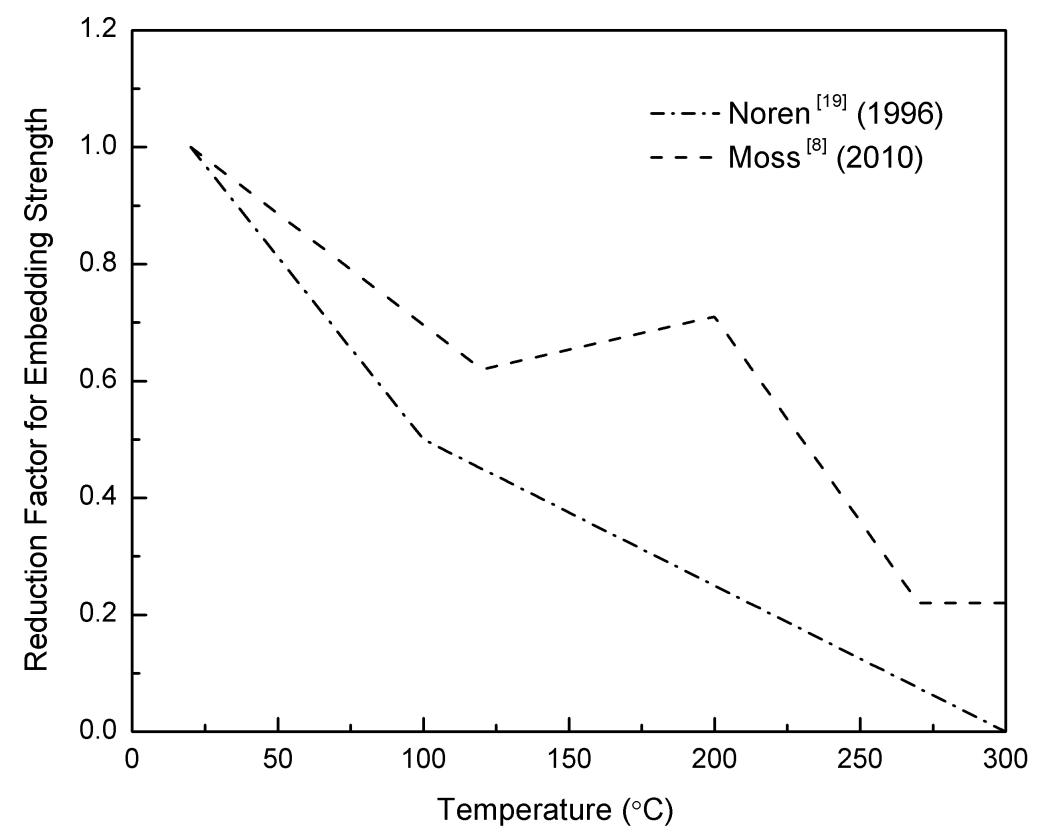

Fig. 2. Reduction factor of embedding strength as a function of temperature.

These two approaches have been compared using the test results of bolted WSW and SWS connections, which were recently carried out in Canada [9]. It was found that Noren's approach seemed to give a more accurate prediction than Moss' approach. In particular, Moss' approach tended to yield a flat curve for a longer exposure time at lower load ratios, because of the assumption of a residual embedding strength at high temperatures. Furthermore, Noren's approach was also adopted by Erchinger [17] to predict the fire resistance rating of timber connections with multiple shear steel-to-wood doweled connections and a mean temperature within the range of $3.5 d$ away from the fastener was used to determine embedding strength.

\section{Component Model}

The component model was developed by Cachim [16] to estimate the fire resistance for doweled timber connections. The model treated a connection as an assembly of individual components: the timber component and the steel dowel component, with their own stiffnesses and strengths. The connection was modeled by discretizing the dowel as a series of beam elements, connected with springs representing the timber behaviour. The component model was firstly verified at room temperature and then used for timber connections at elevated temperatures. The temperature profile within the connection was calculated by carrying out a numerical thermal analysis, using a finite element program.

Besides the empirical models and the analytical models as discussed above, numerical modelling has also been employed to study the fire performance of timber connections. In fact, the finite element approach was used to generate temperature profiles for the structural analytical models $[8,9,16,17]$. In addition, the finite element approach was also used to conduct the thermo-mechanical coupled numerical simulation of timber connections [18]. Although the analytical models and numerical simulations could be used to assess the fire resistance of timber connections, they are based on the 3-D heat transfer analysis and the integration of the strength in each element. That process is very complex for design purposes. Therefore, developing new simple yet accurate calculation methods is also of great importance.

\section{NEW CORRELATIONS}

There is a need for simplified calculation methods, involving the variability of connection types, load ratios, and connection and fastener dimensions, be developed to assess the fire resistance of timber connections.

In this paper, the simplified empirical methods proposed by the authors to estimate fire resistances of WWW, WSW and SWS timber connections using either bolts or dowels as fasteners are presented. The 
calculation methods are developed using data generated from fire experiments in the literature [3-7,9], combined with data obtained from numerical modelling. The modeled results were calculated using the embedment reduction model discussed before (details presented in the literature [9]).

\section{WWW and WSW Connections}

WWW connections and WSW connections are discussed together because they act similarly under fire exposure. For WWW and WSW connections, the central member, either the steel plate or wood member, is protected by the side wood members from direct fire exposure. The performance of the side wood members in fire dominates the failure of the connection rather than the central member. In this matter, similar calculation methods are proposed for WSW and WWW connections with either bolts or dowels as fasteners.

For a given WWW or WSW connection, the fire resistance is assumed to be expressed by the following function:

$t_{f}=f\left(F_{f i}, t_{1}, d\right)$

Define non-dimensional factors: $t^{*}=t_{f} /\left(t_{1} / \beta\right), \eta=F_{f i} / R_{0}$ and $d^{*}=d / t_{1}$ to represent the failure time, the load ratio and the fastener diameter, respectively. Since the side member thickness $t_{1}$ has been incorporated into $t^{*}$ and $d^{*}$ term, Eq. 2 can be rewritten in a dimensionless form as:

$t^{*}=f\left(\eta, d^{*}\right)$

A power law equation is proposed:

$t^{*}=1-(\eta)^{M}\left(d^{*}\right)^{N}$

$M$ and $N$ are connection factors, representing the influence of load ratio $(\eta)$ and non-dimensional bolt diameter $\left(d^{*}\right)$ on the fire performance of timber connections. The larger the $M$ and $N$, the more the influence of the load ratio $(\eta)$ and the non-dimensional bolt diameter $\left(d^{*}\right)$.

Rewriting Eq. .4. in a linear relationship by taking its logarithm, gives:

$\ln \left(1-t^{*}\right)=M \ln (\eta)+N \ln \left(d^{*}\right)$

where $M$ and $N$ can be determined from the fire resistance test data using a best-fitting by the method of least-squares. Since different types of connections may have different values of $M$ and $N$, four pairs of $M$ and $N$ need to be determined individually for WWW and WSW connections with both bolts and dowels, respectively.

The data used to determine $M$ and $N$ are obtained from the literature [3-7,9], including 60 tested and three modeled specimens in total. In the database, the side wood thickness ranges from $45 \mathrm{~mm}$ to $84 \mathrm{~mm}$ for WWW connections, the side wood thickness ranges from $38 \mathrm{~mm}$ to $100 \mathrm{~mm}$ for WSW connections, the fastener diameter ranges from $12 \mathrm{~mm}$ to $20 \mathrm{~mm}$ and the load ratio varies from $10 \%$ to $60 \%$.

The charring rate $\beta$, is approximated as $0.7 \mathrm{~mm} / \mathrm{min}$ for WWW connections and $0.8 \mathrm{~mm} / \mathrm{min}$ for WSW connections based on the results of fire tests. In order to take into account the nonlinear charring rate as a function of time, slightly smaller values are used as $0.65 \mathrm{~mm} / \mathrm{min}$ for WWW connections and as $0.7 \mathrm{~mm} / \mathrm{min}$ for WSW connections, if the fire exposure time is over one hour. The correlation details can be seen in [9]. 
The correlation results show that $M$ and $N$ are found to be 0.1881 and 0.0709 for bolted WWW connections, and 0.1599 and 0.0554 for bolted WSW connections; $M$ and $N$ are found to be 0.4456 and -0.0193 for doweled WWW connections, and 0.3586 and 0.0304 for doweled WSW connections.

It is interesting to note that both $M$ and $N$ factors are close for bolt-type WWW and WSW connections (i.e. $M=0.1881$ vs. 0.1599 ; while $N=0.0709$ vs. 0.0554 ). Similarly, the $M$ and $N$ factors are close for doweltype connections (i.e. $M=0.4456$ vs. 0.3586 ; while $N=-0.0193$ vs. 0.0304 ). Therefore, as a further simplification, $M$ and $N$ are averaged and rounded-off as 0.17 and 0.06 for bolt-type connections, and 0.40 and 0.00 for dowel-type connections, respectively. The values given in Table 1 are found to be a little different in comparison to the values presented in a preliminary analysis [22]. This is due to the fact that new test results have been added to the database and new analyses have been conducted.

Rearranging Eq. 5 to its dimensional form yields the following equation that estimates the fire resistance time of a WWW or WSW connection using either bolts or dowels as fasteners:

$$
t_{f}=(t / \beta)\left(1-\eta^{M}\left(d / t_{1}\right)^{N}\right)
$$

Table 1. Connection factors for timber connections.

\begin{tabular}{|c|c|c|c|c|}
\hline \multirow{2}{*}{} & \multicolumn{2}{|c|}{ WWW Connections } & \multicolumn{2}{c|}{ WSW Connections } \\
\cline { 2 - 5 } & Bolted & Doweled & Bolted & Doweled \\
\hline$\beta(\mathrm{mm} / \mathrm{min})$ & $0.7^{\mathrm{a}}$ & $0.7^{\mathrm{a}}$ & $0.8^{\mathrm{b}}$ & $0.8^{\mathrm{b}}$ \\
\hline$M$ & 0.17 & 0.40 & 0.17 & 0.40 \\
\hline$N$ & 0.06 & 0.00 & 0.06 & 0.00 \\
\hline
\end{tabular}

${ }^{\mathrm{a}} 0.65$ should be used if the fire exposure time is more than $1 \mathrm{~h}$.

${ }^{\mathrm{b}} 0.7$ should be used if the fire exposure time is more than $1 \mathrm{~h}$.

Therefore, Eq. 6, combined with the new average $M$ and $N$ values listed in Table 1, can be used to calculate the fire resistances of WWW and WSW connections. From the equation and the table, one can learn that for doweled WWW and WSW connections, fastener diameter does not play an important role and its effect can be ignored, since $N$ is a very small value (rounded-off to zero). This in accordance with the test results $[3,4]$. However, for bolted timber connections, fastener diameter is an important factor and its effect can not be ignored.

The predicted results using the equation are plotted in Fig. 3, compared to the tested (or modeled) results. Modeled results mean that the results are obtained using the embedment reduction model [9]. It can be seen that the predicted times are mostly within a $\pm 15 \%$ envelope. The symbols tend to scatter almost equally on the both sides of the $45^{\circ}$ reference line.

Although the proposed Eq. 6 is able to predict the fire resistances of WWW and WSW connections, for design purposes, it would be more appreciated if the predicted values are on the conservative side (or underestimated) with a possibility of at least $95 \%$. It is found that if one shifts the predictions downward by $4.0 \mathrm{~min}$, the symbols would scatter underneath the new reference line with a probability of $95 \%$, as shown in Fig. 4. The $4.5(\mathrm{~min})$ is determined as the $95^{\text {th }}$ percentile value for a normal distribution of the predictions about the reference line in Fig. 3. Therefore, a modification or a safety factor is applied to Eq. 6 and it gives a new equation:

$t_{f}=(t / \beta)\left(1-\eta^{M}\left(d / t_{1}\right)^{N}\right)-4.0 \min$

It has to be emphasized that, though the new Eq. 7 does not actually predict the $5^{\text {th }}$ percentile value of the fire resistance rating, it is an attempt to adjust predictions in such away to become more conservative when compared with the available tests (or modeled) data, with a probability of $95 \%$. 


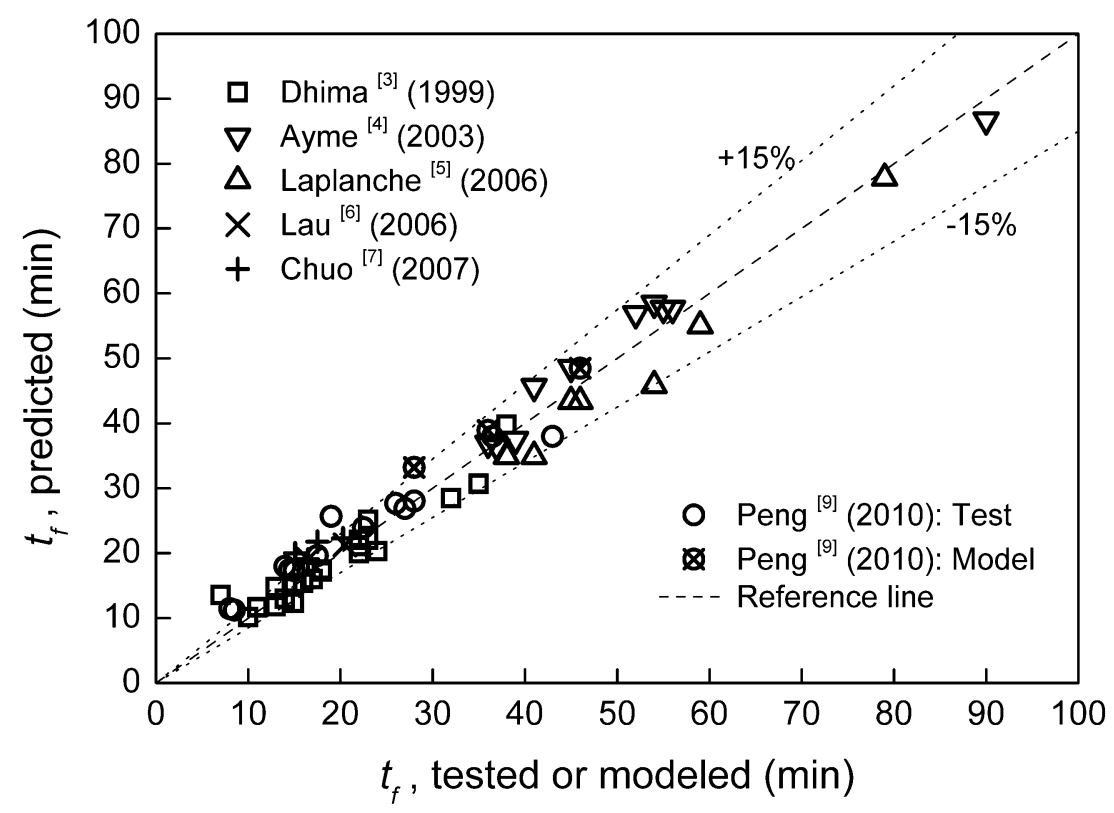

Fig. 3. Comparison between measured or modeled fire resistances and predicted fire resistances using Eq. 6.

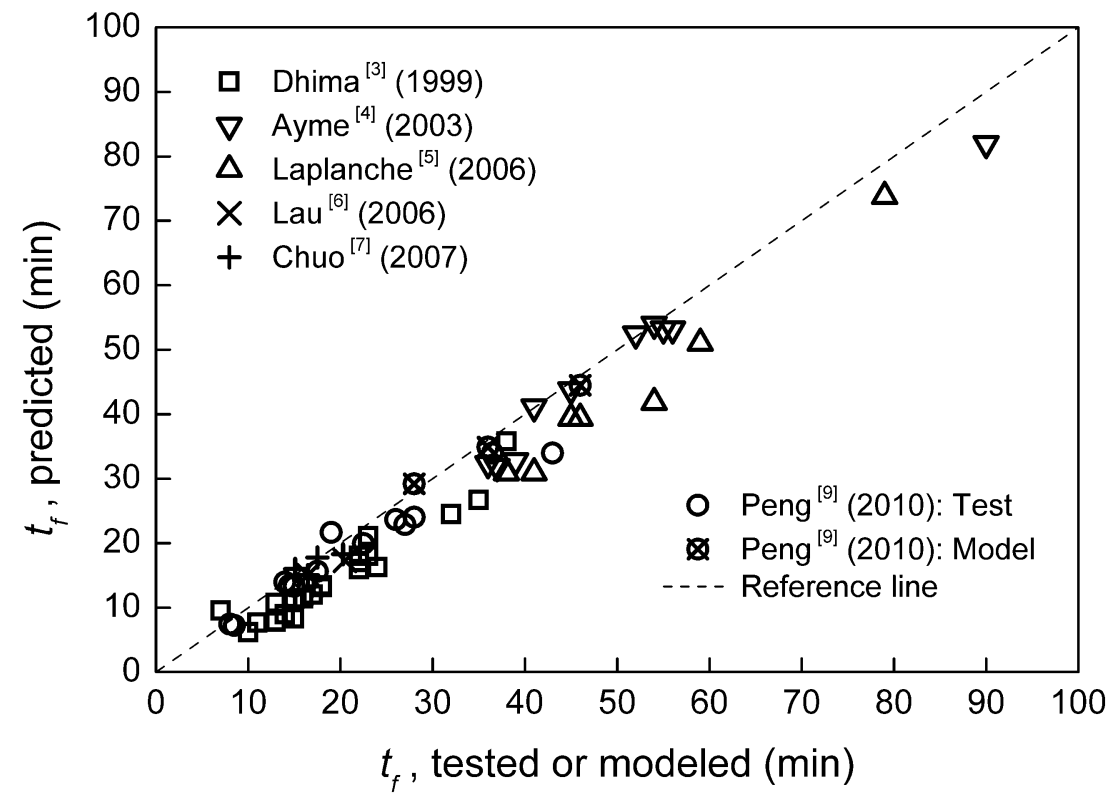

Fig. 4. Comparison between measured or modeled fire resistances and predicted fire resistances using Eq. 7.

\section{SWS Connections}

From the experimental test results [9], the wood member thickness and load ratio played important roles on the fire resistance of a SWS connection. Therefore, a simple equation can be developed by taking into account the effect of wood member thickness and load ratio.

If one plots the failure time $\left(t_{f}\right)$ against the load ratio $(-\ln (\eta))$, it is interesting to see that those data can be fitted into linear curves with different slopes depending on the thickness of wood members $\left(t_{2}\right)$, see Ref. [9] 
for details. Further, it is found that the slope of these linear curves is proportional to the wood thickness. Therefore, if the failure time is plotted as a function of $\left(-\ln (\eta) \cdot t_{2}\right)$, all the data fit into a linear curve.

A simple calculation formula is then proposed to predict the fire resistance of SWS connections:

$t_{f}=-0.0785 \ln (\eta) \cdot t_{2}$

The slope -0.0785 is found by linear regression [9]. The data for regression analysis are obtained from the literature $[6,7,9]$, in total including 7 tested and 15 modeled specimens. In the database, the wood thickness ranges from $63 \mathrm{~mm}$ to $175 \mathrm{~mm}$, the fastener diameter ranges from $12 \mathrm{~mm}$ to $20 \mathrm{~mm}$ and the load ratio varies from $10 \%$ to $30 \%$.

Figure 5 shows the predictions using Eq. 8 versus the tested or modeled fire resistances. Again, modeled results mean that the results are obtained using the embedment reduction model [9]. It can be seen that the predicted fire resistances using Eq. 8 were mostly within the $\pm 10 \%$ envelope.

Similar to WWW and WSW connections, it would be more useful if a modification or safety factor can be introduced to Eq. 8 to ensure that the predications are on the conservative side for design purposes. By shifting the predications downward by $2.0 \mathrm{~min}$, the predicted values scatter underneath the reference line with a probability of $95 \%$, as shown in Fig. 6 . The 2.0 (min) is determined as the $95^{\text {th }}$ percentile value for a normal distribution of the predictions about the reference line in Fig. 5.

$t_{f}=-0.0785 \ln (\eta) \cdot t_{2}-2.0 \mathrm{~min}$

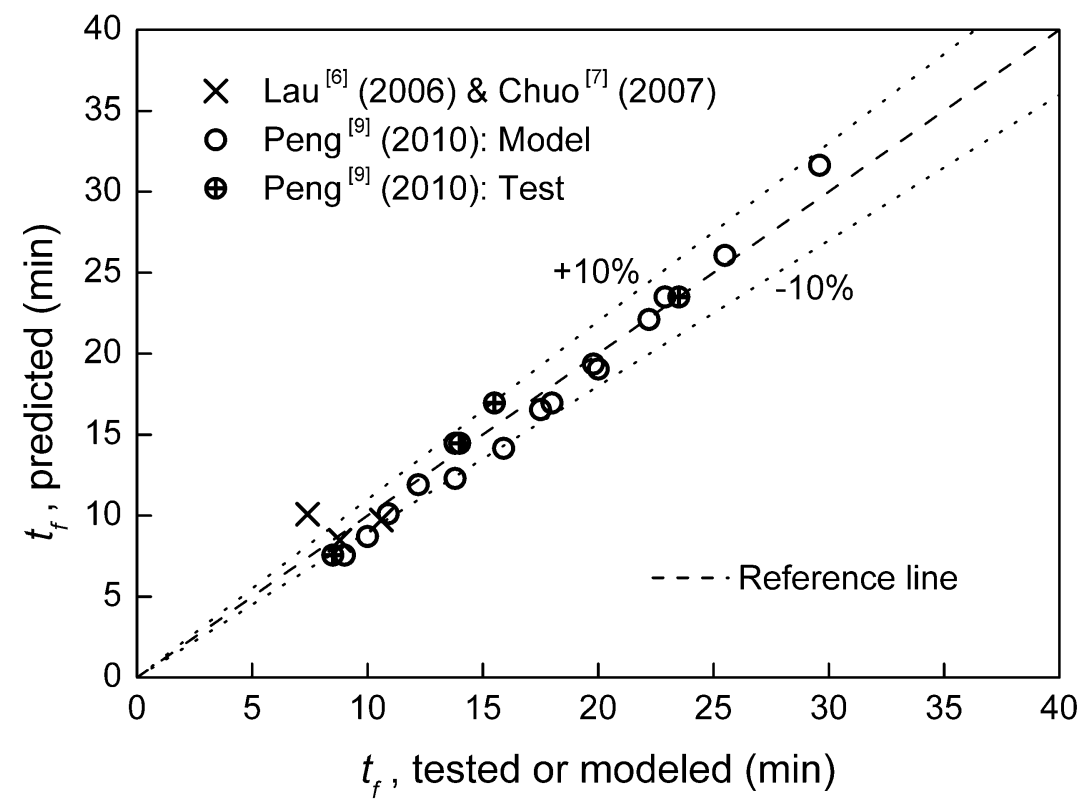

Fig. 5. Comparison between measured or modeled fire resistances and predicted fire resistances using Eq. 8. 


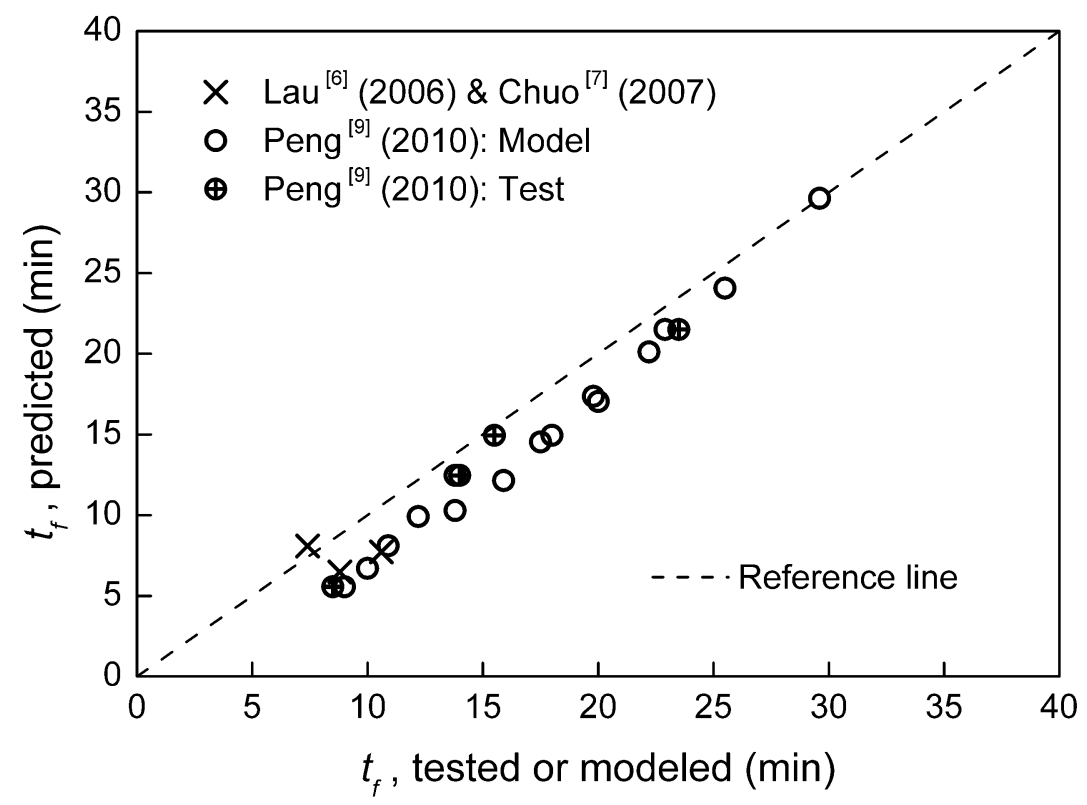

Fig. 6. Comparison between measured or modeled fire resistances and predicted fire resistances using Eq. 9.

\section{PROTECTED CONNECTIONS}

\section{Protective Membrane}

For structural wood members, gypsum boards and plywood panels are two common types of membrane used for fire resistance protection.

The fire resistance tests [9] show that for a single layer of $15.9 \mathrm{~mm}$ thick Type $\mathrm{X}$ gypsum board, the improved fire resistance is about $33 \mathrm{~min}$. This value is very close to the average value ( $33 \mathrm{~min}$ ) for solid wood beams protected with the same protective membrane reported by White [23]. In addition, the $140 / 180{ }^{\circ} \mathrm{C}$ finish rating [24] and the time to reach a temperature of $300{ }^{\circ} \mathrm{C}$ behind the $15.9 \mathrm{~mm}$ Type $\mathrm{X}$ gypsum board were also found to be close to the values reported by White (2009) for solid protected timber beams.

Similar to gypsum board, the fire resistance tests [9] show the improvement for a double-layer of $12.7 \mathrm{~mm}$ thick plywood panels to a timber connection $(15 \mathrm{~min})$ was found to be close to White's result (15 $\mathrm{min})$, as well as the $140 / 180{ }^{\circ} \mathrm{C}$ finish rating and the time to reach a temperature of $300{ }^{\circ} \mathrm{C}$ [23].

Therefore, the additive method, used by White to assess the fire resistances of wood beams with protective membranes, can be used to estimate the fire resistances of protected timber connections, as shown in Eq. 10:

$$
t_{f, \text { protected }}=t_{a}+t_{f}
$$

where $t_{a}$ is the time assigned to different types of protective membranes (i.e. $30 \mathrm{~min}$ for a single-layer of $15.9 \mathrm{~mm}$ Type $\mathrm{X}$ gypsum board, and $15 \mathrm{~min}$ for a double-layer of $12.7 \mathrm{~mm}$ plywood panels), and $t_{f}$ is the fire resistance of unprotected timber connections, which can be calculated using Eq. 7 for WWW and WSW connections or Eq. 9 for SWS connections.

It is interesting to see from Eq. 10 that a connection protected with a layer of $15.9 \mathrm{~mm}$ Type X gypsum board has a fire resistance less than $1 \mathrm{~h}$, if $t_{f}$ itself is less than $30 \mathrm{~min}$. However, for the same connection, using the TR 10 requirement would result in an overestimated fire resistance, which is $1 \mathrm{~h}$. 


\section{Concealed Fasteners}

Although timber connections with concealed fasteners have not received necessary study, it is worth discussing the effect of this type of protection on the fire resistances for WWW or WSW connections, based on the knowledge and information generated in the research [9].

Figure 7 shows a WSW connection with a concealed bolt or dowel as an example. Wood plugs are used to cover the holes. The original thickness of the wood side member is $t_{1}+a$, but the effective bearing thickness is $t_{l}$. A concealed timber connection can be recognized as an equivalent timber connection with the wood side member thickness of $t_{l}$, protected with additional wood with a thickness of $a$.

Generally, timber connections with concealed fasteners have the advantages that they have no metal directly exposed to fire, and also have a nice appearance. It is assumed that the additive method used for timber connections with protective membranes can be used to calculate the fire resistance of WWW and WSW connections with concealed fasteners, as shown in Eq. 10. The parameter $t_{a}$ is the fire resistance provided by the side wood with a thickness of $a$. In Eurocode 5, a charring rate 0.9 or $1.0 \mathrm{~mm} / \mathrm{min}$ is recommended to calculate the extra fire resistance provided by wood-based panels or plywood panels attached to main members. However, for timber connections with concealed fasteners, the solid wood part $a$ is a part of the mean member. It will not fall off during a test like wood-based panels. Therefore, a lower value of $0.7 \mathrm{~mm} / \mathrm{min}$, as close to the charring rate of solid timber might be suitable to be used to calculate the extra fire resistance provided by the additional wood with a thickness of $a$. However, further fire resistance tests are necessary to validate this assumption to use the additive method for timber connections with concealed fasteners.

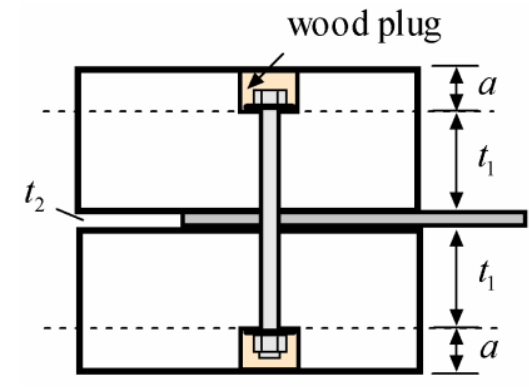

(a)

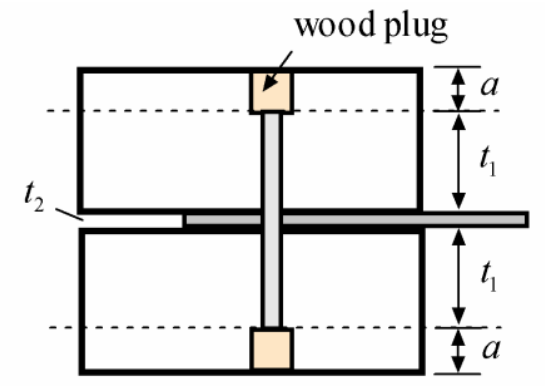

(b)

Fig. 7. Concealed fasteners in WSW connections: (a) concealed bolt; (b) concealed dowel.

\section{Intumescent Paint}

Intumescent paint can be used to increase the fire resistance duration of steel members. When intumescent paint is heated, the material swells up into a significant thickness and chars. It acts as a thermal barrier and insulates the structural members beneath.

Fire resistance tests show that a SWS timber connection, with side steel plates and bolt heads/nuts protected with $2 \mathrm{~mm}$ thick intumescent paint, only increased the fire resistance by $7 \mathrm{~min}$ [9]. It was observed in the test that the displacement between the steel plate and the wood member during the fire test caused adhesion problem to the intumescent paint. The paint was therefore damaged at the edges of the steel plate, leaving the steel plate exposed to the fire at this area. For comparison, Lau [6] found that the improved fire resistance for bolted SWS connections and the nailed steel-wood-steel connections were about 9.9 min and $8.2 \mathrm{~min}$, respectively. Frangi [25] stated that the protection of a $2 \mathrm{~mm}$ thick intumescent paint to steel side plates increased the fire resistance of nailed SWS connections by about $18 \mathrm{~min}$.

Thus, using intumescent paint to protect steel plates may not be a good solution for timber connections with steel side plates, due to the adhesion problem of intumescent paint at the steel plate edges.

\section{CONCLUSION}

This paper first reviewed existing calculation models developed in prediction of the fire resistances of double-shear timber connections. Based on the existing fire resistance data generated in recent years, new correlations are presented for assessing the fire resistances of unprotected WWW, WSW and SWS 
connections using bolts or dowels as fasteners. Load ratio, wood member thickness and fastener diameter are taken into account in the correlations. Comparison with experimental results showed that the method could reasonably predict the fire resistances of WWW and WSW connections with an accuracy of about $\pm 15 \%$ and the method could predict the fire resistances of SWS connections with an accuracy of about $\pm 10 \%$. In addition, the method can be modified by introducing safety factors to ensure the predictions are on the conservative side.

For timber connections with protective membranes, such as Type X gypsum boards and plywood panels, the additive method can be used by adding the additive fire resistances of protective membranes to the fire resistances of unprotected timber connections. The fire resistances of a single layer of $15.9 \mathrm{~mm}$ Type X gypsum board and a double layer of $12.7 \mathrm{~mm}$ plywood are about $30 \mathrm{~min}$ and $15 \mathrm{~min}$, respectively.

With the calculation methods developed to predict the fire resistances of timber connections, recommendations can be made on how to design suitable timber connections in compliance with code requirements.

For unprotected timber connections, increasing the wood member thickness, diameter of fasteners and number of fasteners would be possible solutions to achieve code requirements. The diameter and number of fasteners do not have direct impact on the fire resistance of timber connections loaded at the same load ratio. However, by increasing the diameter or number of fasteners, the ambient load capacity of timber connections is actually increased, and therefore the load ratio is deceased. This lower load ratio results in an increase in the fire resistance. To achieve a better fire resistance, dowels are a good solution instead of bolts for the same wood member thickness, diameter and number of fasteners.

If appearance is not a factor, protective membranes can be used to increase the fire resistance of timber connections. The additive method can be used to calculate the fire resistance of protected timber connections. If appearance is a factor, fasteners can be concealed within wood members and wood plugs can be used to cover the fasteners. The additive method can also be used to calculate the fire resistances of concealed timber connections.

\section{REFERENCES}

[1] Carling, O., "Fire resistance of joint details in load bearing timber construction - a literature survey", BRANZ Study Report SR 18, Building Research Association of New Zealand, New Zealand, 1989.

[2] Kruppa, J., Lamadon, T. and Rachet, P., "Fire Resistance Test of Timber Connections", CTICM Ref. INC-00/187-JK/NB, CTICM, Paris, France, 2000.

[3] Dhima, D., "Vérification expérimentale de la résistance au feu des assemblages d'éléments en bois", CTICM Ref. INC-99/399-DD/NB, CTICM, Paris, France, 1999.

[4] Ayme, N., "Assemblages bois-métal en double cisaillement", Rapport Du Comportement Au Feu D’Assemblages Bois, CTICM Ref. SR21-03/121-NA/PB, CTICM, Paris, France, 2003

[5] Laplanche, K., "Fire performance of timber connections: experimental and modelling approach", Ph.D. Thesis, Clermont-Ferrand: Blaise Pascal University (in French), 2006.

[6] Lau, P.H., "Fire resistance of connections in laminated veneer lumber", Fire Engineering Research Report 06/3, Dept. of Civil Engineering, University of Canterbury, New Zealand, 2006.

[7] Chuo, T.C.B., "Fire performance of connections in LVL structures", Fire Engineering Research Report 07/4, Dept. of Civil Engineering, University of Canterbury, New Zealand, 2007.

[8] Moss, P., Buchanan, A., Fragiacomo, M., and Austruy, C., (2010) Experimental Testing and Analytical Prediction of the Behaviour of Timber Bolted Connections Subjected to Fire, Fire Technology, 46(1): p. 129-148, http://dx.doi.org/10.1007/s10694-009-0096-6

[9] Peng, L., "Performance of heavy timber connections in fire", Ph.D. Thesis, Carleton University, Ottawa, Canada, 2010.

[10] ISO834-1, Fire resistance tests - Elements of building construction, Part 1: General requirements, International Organization for Standardization, Switzerland, 1999. 
[11] ASTME119, Standard methods of fire tests of building constructions and materials. American Society for Testing and Materials, West Conshohochen, PA, USA, 2007.

[12] NBCC, National Building Code of Canada in Canadian Commission on Building and Fire Code, National Research Council of Canada, Ottawa, ON, Canada, 2005.

[13] Mehaffey, J.R., "Fire performance of heavy timber connections", Report No. 3223, Forintek Canada Corp., Ottawa, ON, Canada, 2003.

[14] AWC, "Calculating the fire resistance of exposed wood members", Technical Report 10 (TR10), American Wood Council, American Forest and Paper Association, Washington, DC, 2003.

[15] EN1995-1-2, Eurodode 5 - Design of timber structures, Part 1-2: Structural fire design, CEN, Brussels, Belgium, 2004.

[16] Cachim, P.B. and Franssen, J.M., (2009) Numerical modelling of timber connections under fire loading using a component model, Fire Safety Journal, 44(6): p. 840-853, http://dx.doi.org/10.1016/j.firesaf.2009.03.013

[17] Erchinger, C., Frangi, A. and Fontana, M., (2010) Fire design of steel-to-timber dowelled $\begin{array}{lllll}\text { connections, } & \text { Engineering } & \text { Structures, } & \text { 32(2): }\end{array}$ http://dx.doi.org/10.1016/j.engstruct.2009.11.004

[18] Racher, P., Laplanche, K., Dhima, D., and Bouchaï, A., (2010) Thermo-mechanical analysis of the fire performance of dowelled timber connection, Engineering Structures, 32(4): p. 1148-1157, http://dx.doi.org/10.1016/j.engstruct.2009.12.041

[19] Noren, J., (1996) Load-bearing capacity of nailed joints exposed to fire, Fire and Materials, 20: p. 133-143, http://dx.doi.org 10.1002/(SICI)1099-1018(199605)20:3<133::AID-FAM565>3.0.CO;23

[20] Konig, J. and Fontana, M., "The performance of timber connections in fire test results and rules of Eurocode 5", Proceedings of International Rilem Symposium 'Joints in Timber Structures'. University of Stuttgart, Rilem Publications s.a.r.l., Cachan, France, 2001.

[21] Johansen, K.W., "Theory of timber connectors", International Association of Bridge and Structural Engineering (IABSE). Bern, Switzerland, 1949.

[22] Peng, L., Hadjisophocleous, G., Mehaffey, J., and Mohammad, M., (2010) Fire resistance performance of unprotected wood-wood-wood and wood-steel-wood connections: A literature review and new data correlations, Fire Safety Journal, 45(6-8): p. 392-399, http://dx.doi.org/10.1016/j.firesaf.2010.08.003

[23] White, R.H., "Fire resistance of wood members with directly applied protection", Fire and materials 2009: 11th International Conference and Exhibition. Fisherman's Wharf, San Francisco, USA, 2009.

UL, Fire Resistance Directory, in Vol. 1, Underwriters Laboratories, 1993

Frangi, A., Erchinger, C. and Fontana, M., (2009) Experimental fire analysis of steel-to-timber connections using dowels and nails, Fire and Materials, 34(1): p. 1-19, http://dx.doi.org/10.1002/fam.994 